\title{
Понятие «международное торговое право»
}

Тюрина H.E.

В статье представлены результаты исследования особенностей международного торгового права, обусловленные глобализацией международной торговли. Отмечаются особенности юридического содержания некоторых принципов международного торгового права, его функций, субъектов и метода. Рассматривается соотношение права ВТО и международного торгового права.

Ключевые слова: международное торговое право; право ВТО; право международной торговли; таможенные территории; наднациональность.

В современный период динамично развивающимся сегментом международного права является его отрасль - международное экономическое право ${ }^{1}$ в частности торговое право. Особенности, отмечаемые в правовом регулировании международной торговли, свидетельствуют о том, что в международном торговом праве происходят изменения, которые не наблюдаются, во всяком случае столь явно, в других отраслях. Вместе с тем изменяющееся международное торговое право не вступает в противоречие с общепризнанными принципами и общей концепцией международного права. Эта совместимость дает основание полагать, что изменения в международном торговом праве есть реализующийся потенциал международного права в условиях, определяющих направление мирового развития в современный период, а именно в процессе глобализации.

Рассмотрим специфику международного торгового права в аспектах, определяющих структуру правовой парадигмы, - контентном, ценностном и организационном.

В контентном аспекте необходимо обратить внимание прежде всего на особенности юридического содержания некоторых принципов международного торгового права, которые, как и другие отраслевые принципы, развивают и конкретизируют основные принципы международного права применительно к соответствующим отношениям.

\footnotetext{
* Тюрина Наталия Евгеньевна - к.ю.н., доцент кафедры международного и европейского права Казанского (Приволжского) федерального университета. tyurina.natal@yandex.ru. 1 Вылегжанин А.Н., Лабин Д.К., Шумилов В.М. Международное экономическое право. М.: МГИМО (У) МИД России, 2012. С. 3 и сл.
} 
Нельзя не заметить, что основные принципы международного права, получившие закрепление еще в Уставе ООН 1945 г. и предназначенные для всей сферы действия международного права, вырабатывались в условиях политической напряженности, существенных различий национальных социально-экономических систем. Это сказалось на их содержании, в котором ключевым моментом является суверенное равенство, незыблемость государственного суверенитета.

Между тем объективная экономическая взаимозависимость государств и высокая заинтересованность в торгово-экономических связях послужили предпосылкой для такой формы реализации суверенитета, в которой существенное место занимает добровольный отказ от определенных суверенных прав, получивший воплощение в некоторых принципах международного торгового права и формах торгово-экономического сотрудничества.

Так, принцип либерализации международной торговли не позволяет устанавливать внутренние экспортно-импортные правила, создающие препятствия международной торговле; обязывает к снижению уровня таможенного обложения в отношении предметов импорта; ограничивает право на применение контрмер в условиях, когда предусмотрено одностороннее отступление от установленных требований. Такие обязательства непосредственно затрагивают сферу внутригосударственного регулирования, в которой государство традиционно осуществляло верховенство. Однако указанные ограничения для отдельно взятого государства компенсируются дополнительными возможностями, открывающимися в результате аналогичных ограничений, существующих для других государств.

Принцип преференций в торговле с развивающимися странами, по сути, ведет к нарушению баланса прав и обязанностей и установлению юридического неравенства торговых партнеров. Тем не менее это не влияет на общий международно-правовой статус государств, предоставляющих преференции, и не составляет нарушения принципа суверенного равенства государств. Предоставление преференций является результатом добровольного волеизъявления, не ограничивающим права соответствующего государства на дальнейшее участие в процессе принятия согласованных решений.

Отказ от некоторых суверенных прав имеет место также при передаче отдельных государственных полномочий органам международных организаций экономической интеграции, в результате чего государства 
становятся обязанными следовать нормативным установлениям наднациональных предписаний.

Иногда приведенные факты толкуются как ограничение государственного суверенитета или его утрата. Однако, как можно заметить, во всех случаях «ограничения» суверенитета есть проявление доброй воли. В данных обстоятельствах говорить даже о частичном ограничении суверенитета представляется некорректным с учетом его неделимости. «Самоограничение» тоже не совсем подходящий термин, поскольку то, что происходит в контексте «ограничений суверенитета», обусловлено объективной необходимостью в новой модели межгосударственных отношений, являющейся ответом на вызовы возрастающей взаимозависимости. Получается, что, соглашаясь на подчинение внутреннего законодательства международно-правовым установлениям, на отказ от взаимности, на соблюдение наднациональных предписаний, государства делают осознанный (суверенный) выбор, продиктованный логикой сотрудничества и открывающий для них новые возможности в достижении целей внутригосударственного развития.

Приведенные принципы международного торгового права, в которых, на первый взгляд, может усматриваться некоторое противоречие основным принципам международного права, ставят во главу угла достижение специфических целей без какого-либо ущерба международному праву в целом.

Особенностью содержания современного международного торгового права является также право Всемирной торговой организации (BТО), в котором принципы международного торгового права получили договорное закрепление.

Специфика ВТО как международной институции вызвала дискуссию о соотношении права ВТО с международным правом. И поскольку прямого ответа на этот вопрос документы ВТО не дают, попытаемся найти его, исходя из общепризнанных норм и устоявшихся положений теории международного права.

Статья 103 Устава ООН устанавливает, что в случае противоречия обязательств по Уставу обязательствам по какому-либо иному международному соглашению преимущественную силу имеют обязательства по Уставу². Следовательно, соглашения между членами ВТО,

\footnotetext{
${ }^{2}$ Устав Организации Объединенных Наций от 26 июня 1945 г. // Сборник действующих договоров, соглашений и конвенций, заключенных СССР с иностранными государствами. Вып. ХП. М., 1956.
} 
являющиеся по своей юридической природе международными договорами, не могут составлять исключение из этого правила, что находит подтверждение и в ГАТТ 1947/1994. Так, ст. ХХІ (c) ГАТТ гласит: «Ничто в настоящем соглашении не должно быть истолковано: ...как препятствующее какой-либо Договаривающейся Стороне предпринимать какие-либо действия во исполнение ее обязательств на основании Устава Организации Объединенных Наций для сохранения международного мира и безопасности» ${ }^{3}$.

В ряде многосторонних торговых соглашений членов ВТО также упоминается, что участие в них не освобождает стороны от обязательств по международным договорам, не входящим в систему $\mathrm{BTO}^{4}$. В частности, вряд ли можно оспаривать то, что к рассматриваемым соглашениям подлежат применению положения Венской конвенции о праве международных договоров 1969 г., поскольку Венская конвенция не содержит каких-либо исключений, которые могли бы быть использованы в отношении соглашений членов ВТО. Напротив, в ст. 5 Конвенции зафиксировано: «Настоящая конвенция применяется к любому договору, являющемуся учредительным актом международной организации, и к любому договору, принятому в рамках международной организации, без ущерба для соответствующих правил данной организации» ${ }^{5}$.

Приведенное указание имеет существенное значение для подтверждения связи между правом ВТО и международным правом, поскольку оно обязывает при толковании соглашений членов ВТО руководствоваться п. 3 (с) ст. 31 Венской конвенции, где говорится, что при толковании международных договоров необходимо принимать во внимание любые относящиеся к данному случаю нормы международного права, т.е. соглашения членов ВТО должны толковаться в контексте других норм международного права.

Из ст. 5 Венской конвенции следует, что к соглашениям членов ВТО применима и ст. 30 данного документа, посвященная разрешению нормативных коллизий. На основании этой статьи должны разрешаться коллизии между соглашениями членов ВТО и другими международными договорами и коллизии между разными соглашениями членов ВТО,

\footnotetext{
${ }^{3}$ Генеральное соглашение по тарифам и торговле 1947 // http://www.mineconomy.am/ files/news/425_ru.pdf

${ }^{4}$ См.: Тюрина Н.Е. Международная торговля как фактор развития международного публичного права. Казань, 2009. С. 67.

${ }^{5}$ Венская конвенция о праве международных договоров от 23 мая 1969 г. // Ведомости Верховного Совета СССР. 1986. № 37. Ст. 772.
} 
если иное прямо не предусмотрено в праве ВТО. Поскольку правом ВТО регулируются торговые отношения более полутораста субъектов международного права, можно утверждать, что оно и есть современное международное торговое право, взаимодействие которого со всем международным правом носит характер взаимодействия части и целого.

Ценностный аспект международного торгового права можно проследить через выполняемые им функции. Важнейшей сочиильной функцией этого права является укрепление и развитие международной торговой системы, от состояния которой во многом зависит прочность экономической базы государства и уровень жизни населения. Торговля - это по сути отношения сотрудничества. Международноправовое регулирование международной торговли, осуществляемое в целях ее развития, способствует поддержанию мира и защите таких общечеловеческих ценностей, как человеческая жизнь, здоровье, безопасность, трудовая занятость, духовное развитие, социальные блага. В этом контексте международное торговое право выполняет гуманитарную функцию. Гуманитарное измерение международной торговли в широком смысле, включая защиту прав человека в любых обстоятельствах, может и должно быть главным тестом на право осуществления тех или иных торгово-экономических мероприятий и принятия нормативных установлений на всех уровнях. Правовые основы для достижения этой цели были заложены в тексте ГАТТ 1947 г. и не утрачивают своего значения в настоящее время. Соответствующие положения получили закрепление в преамбуле и ст. XX (b) ГАТТ, ст. XIY Генерального соглашения по торговле услугами (ГАТС $)^{6}$, ст. ХШ Соглашения по правительственным закупкам (СПЗ) ${ }^{7}$, ст. 27.2 Соглашения по торговым аспектам интеллектуальной собственности (ТРИПС) ${ }^{8}$. В указанных статьях предусматриваются исключения из общих правил в пользу соблюдения прав человека.

Несмотря на то что последовательная и устойчивая практика толкования данных статей в контексте норм международного права о правах человека в ВТО еще не сложилась, можно утверждать, что международное торговое право обладает большим гуманитарным (в широком смысле) потенциалом.

${ }^{6}$ General Agreement on Trade in Services 1994//http://www.wto.org.

${ }^{7}$ Agreement on Government Procurement 1994//http://www.wto.org.

${ }^{8}$ Agreement on Trade-Related Aspects of Intellectual Property Rights 1994//http://www. wto.org. 
Исходя из допустимости указанных исключений, в национальном законодательстве закрепляются положения, которые можно назвать гуманитарными в широком смысле оговорками. Так, согласно ст. 32 и 35 Федерального закона РФ «Об основах государственного регулирования внешнеторговой деятельности» от 8 декабря 2003 г. меры, затрагивающие внешнюю торговлю, могут вводиться, если они необходимы для охраны или здоровья людей, обороны страны и безопасности государства 9 .

Разновидностью гуманитарных оговорок являются социальные оговорки. Обязательства, основанные на социальной оговорке, требуют соблюдения международных стандартов в сфере труда. Однако исполнение таких требований во многом зависит от экономических возможностей государства, поэтому гуманитарная ценность социальных оговорок для развивающихся стран представляется сомнительной. В то же время стремление увязывать соблюдение международных стандартов в сфере труда с предоставлением торговых преимуществ указывает на тенденцию к использованию торгового права в качестве инструмента решения социальных проблем.

Не менее важной и столь же острой проблемой, рассматриваемой на современном этапе в связи с международной торговлей и правами человека, является экологическая безопасность. Индивидуальные торговые интересы государств и бизнеса зачастую вступают в противоречие с интересами экологической безопасности. В этих условиях с позиции общечеловеческих интересов необходимо признание исключений из принципа либерализации международной торговли в пользу соблюдения норм международного экологического права и соответствующих им национальных экологических стандартов. Однако единые стандарты в этой области для развитых и развивающихся стран ведут к нарушению принципа взаимной выгоды. Между тем в двухсторонних отношениях уже имеют место случаи лишения торговых преимуществ за нарушение экологических норм.

Учитывая неоднозначность последствий как либерализации, так и исключений из данного принципа в целях защиты окружающей среды $^{10}$, нельзя не заметить, что международное торговое право, посред-

${ }_{9}^{9}$ Об основах государственного регулирования внешнеторговой деятельности: Ф3 от 8 декабря 2003 г. № 164-Ф3 // Собрание законодательства Российской Федерации. 2003. № 50. C. $4850 ; 2004$. № 35. Ст. 3607.

${ }^{10}$ Предложения о проведении анализа торговых соглашений с целью оценки указанных последствий вызывают протест со стороны развивающихся стран из-за опасений потери преимуществ на мировом рынке в случае повышения экологических требований 
ством которого предпринимаются попытки достижения указанных целей, приобретает экологическую функцию.

Предпосылки к выполнению международным торговым правом новых функций коренятся в особенностях его организационного компонента, которые связаны с субъектами, методами и местом в юридической конструкции «право международной торговли».

$\boldsymbol{O}$ субъектах. С позиции международного торгового права, существенной частью которого является право ВТО, государство - это прежде всего самостоятельная таможенная территория, границы которой устанавливают пределы национального регулирования экспортно-импортных операций, а органы власти обладают достаточной компетенцией для выполнения обязательств члена ВТО. Таким образом, для характеристики государства как субъекта международного экономического (торгового) права таможенная территория является важным специфическим атрибутом.

Наряду с государствами в международных торговых отношениях участвуют самостоятельные таможенные территории, не являющиеся государствами. Это производные от государств образования двух типов.

Первый тип возникает в результате согласованного волеизъявления государств и представляет собой особую разновидность международных организаций; второй тип - территориальное образование, создаваемое односторонним волеизъявлением государства. Рассмотрим каждый из них.

В научной литературе неоднократно отмечалось, что международные экономические организации в настоящее время имеют две принципиальные разновидности: организации традиционного типа и организации экономической интеграции. Закономерным этапом развития интеграционных объединений является образование таможенного союза с заменой таможенных территорий государств-членов единой таможенной территорией. Такие объединения - самостоятельные таможенные территории - могут быть членами ВТО, других международных организаций, участниками международных договоров ${ }^{11}$. Подтверждаемая таким образом международная право- и дееспособность таможенных союзов позволяет причислить их к субъектам международного

к этим странам. См.: Salzman J. Executive Order and the Environmental Review of Trade Agreements//AJIL. 2001. Vol. 95. № 2. P. 380.

${ }^{11}$ См.: Тюрина Н.Е. Международная правосубъектность таможенных союзов // РЕМП 2010. СПб, 2011. С. 223-233. 
экономического (торгового) права и рассматривать как разновидность производных субъектов международного права.

Второй тип производных от государства образований представляют обособленные таможенные территории, сформированные односторонним волеизъявлением государства. Такие территории в политическом аспекте являются частью государства, в котором они выделяются в самостоятельную административно-экономическую единицу. Такие территории наделяются правоспособностью вступать во взаимоотношения с другими государствами, проводя собственную торговую политику и осуществляя регулирование внешнеторговой деятельности на основе собственного законодательства, что позволяет им в соответствующей сфере выступать на равных началах с государствами.

Олицетворением такого рода участников международных торговых отношений являются китайские территории Гонконг, Макао и Тайпей, каждая из которых состоит в двухсторонних договорных отношениях с отдельными государствами и обладает членством в ВТО. Международная деятельность данных образований свидетельствует о наличии у них международной право- и дееспособности и дает основание для признания их субъектами международного торгового (и шире - экономического) права.

С учетом того, что торгово-экономическое сотрудничество является важной составляющей объекта международно-правового регулирования, учет особенностей международного торгового права, связанных с его субъектами, служит адекватному отражению в теории международного права состояния международной действительности и развитию научных представлений о международной правосубъектности.

$\boldsymbol{O}$ методе. По способам воздействия на соответствующие отношения международное торговое право отличается от других отраслей тем, что в этой области получил наиболее заметное развитие наднациональный метод регулирования. Его применение связано прежде всего с деятельностью международных организаций различной степени экономической интеграции, начиная с таможенных союзов, участники которых наделяют органы этих организаций правотворческими функциями. Акты, принимаемые данными органами, имеют обязательную силу для государств - членов организации. Такое представление о наднациональном методе излагается в учебно-методических и научных 
публикациях по международному праву ${ }^{12}$. Однако с учетом практики ВТО оно является неполным.

ВТО иногда характеризуют как международную организацию наднационального типа, несмотря на то, что органы этой организации не наделены правотворческой функцией. Однако обоснование указанной характеристике существует. Как представляется, оно состоит в том, что члены ВТО согласно Марракешскому соглашению о создании Всемирной торговой организации от 15 апреля 1994 г. обязаны приводить свое законодательство в соответствие с многосторонними соглашениями, принятыми в этой организации. Таким образом, предусмотренная международным правом в обобщенном виде обязанность государств добросовестно выполнять свои международные обязательства в ВТО дополняется императивным предписанием способа исполнения, выражающим приоритет права ВТО над национальным правом.

Как метод наднациональное регулирование имеет производный характер от координационного метода, что исключает основание для противопоставления его юридической природе международного права. Отмечаемый производный характер наднационального метода указывает на то, что он не отменяет и не заменяет координационный метод и, следовательно, является субсидиарным по отношению к нему. Применение данного метода ограничено отношениями между членами определенного объединения - субъекта международного права, причем такие объединения могут возникать не только на региональном, но и на универсальном уровне.

Дополнение координационного метода наднациональным методом ведет к изменению качества соответствующего правового регулятора. Так, универсальный характер права ВТО, обусловленный его природой, усиливается за счет признания его приоритета над национальным правом.

Особенности метода международного торгового права, не противоречащие общему методу международного права, позволяют сделать вывод о том, что способы международно-правового регулирования не ограничиваются теми, которые уже получили признание

12 Лукашук И.И. Международное право. Общая часть. М., 1996. С. 166; Моисеев А.А. Суверенитет государств и надгосударственность международных организаций // Международные отношения и право: взгляд в XXI век / International Relations and Law: A Look into XXI Century. Материалы конференции в честь профессора Л.Н. Галенской / Под ред. С.В. Бахина. СПб, 2009. С. 195. 
в доктрине международного права, и что практика воздействия на международные торговые отношения может получить распространение и в других сферах.

Регулируя межгосударственные отношения, международное торговое право способствует формированию благоприятных условий для совершения международных торговых сделок, закрепляет поддерживаемые государствами интересы бизнеса, обеспечивает защиту неторговых интересов, затрагиваемых в процессе осуществления международного товарообмена. Решение названных вопросов средствами международного права продиктовано необходимостью поддержания международного правопорядка, существенным элементом которого является международный торговый порядок.

Роль международного торгового права в упорядочении отношений между негосударственными субъектами состоит в том, что его источники - международные договоры - являются формой унификации норм международного частного права. В результате международное торговое право, имплементированное в национальные правовые системы, выступает регулятором гражданско-правовых отношений, осложненных иностранным элементом.

Внутригосударственные отношения в области внешнеторговой деятельности в настоящее время также в значительной мере подвергаются воздействию международного торгового права, которое обусловлено обязательствами государств, основанными на международных договоpax. Это обязательства в сфере таможенного, нетарифного, антидемпингового регулирования, регулирования субсидируемого импорта, технических барьеров, правительственных закупок, торговли отдельными видами товаров, защиты связанных с торговлей интеллектуальных и инвестиционных прав и др.

Юридико-технический инструментарий, посредством которого нормы международного торгового права имплементируются в международное частное и национальное право, может быть различным, однако его проникновение как исходного нормативного начала в указанные правовые системы становится все более и более очевидным. В свете выделенных особенностей современное международное торговое право в организационном аспекте предстает как универсальный правовой регулятор.

По мнению автора, особенности международного торгового права, отмечаемые во всех трех аспектах, обусловлены объективным 
процессом глобализации международной торговли. Однако этот процесс не ограничивается рамками отдельной сферы. Постепенно он захватывает и другие области межгосударственного взаимодействия. Из этого вытекает, что многие изменения, происходящие в международном торговом (и шире - экономическом) праве, следует ожидать и в других отраслях международного права, и они должны учитываться в определении национальной внешней стратегии. Прогнозирование изменений в других отраслях с учетом тех, которые уже имеют место в международном торговом праве, могло бы способствовать решению данной задачи.

\section{Библиографический список}

Вылегжанин А.Н., Лабин Д.К., Шумилов В.М. Международное экономическое право. М. МГИМО(У) МИД России. 2012.

Лукашук И.И. Международное право. Общая часть. М.: БЕК, 1996.

Моисеев А.А. Соотношение суверенитета государств и надгосударственности международных организаций // Международные отношения и право: взгляд в XXI век/International Relations and Law: A Look into XXI Century. Материалы конференции в честь профессора Л.Н. Галенской / Под ред. С.В. Бахина. СПб, 2009. С. 183-197.

Тюрина Н.Е. Международная правосубъектность таможенных союзов // Российский ежегодник международного права 2010. СПб: Россия-Нева, 2011. С. 223-233.

Тюрина Н.Е. Международная торговля как фактор развития международного публичного права. - Казань: Центр инновационных технологий, 2009.

Salzman J. Executive Order and the Environmental Review of Trade Agreements //American Journal of International Law. 2001. Vol. 95. N 2. P. 366-380. 


\section{The Concept of International Trade Law (Summary)}

\section{Nataliya Y. Tyurina*}

The article attempts at forecasting the development of international trade law, affected by the process of globalization. The author points out the contents of certain principles, functions, subjects and method of international trade law and considers the relation between the WTO law and international law.

Keywords: international trade law; WTO law; law of international trade; custom territories; super nationalism.

* Natalya Y.Tyurina - Ph.D. in Law, associate professor of the Chair of International and European law, Kazan (Volga region) Federal University. tyurina.natal@yandex.ru. 